\title{
Management of Complicated Choledochal Cysts
}

\author{
Richa Lal Shaleen Agarwal Rakesh Shivhare Ashok Kumar \\ Sadiq S. Sikora Vinay K. Kapoor Rajan Saxena \\ Department of Surgical Gastroenterology, Sanjay Gandhi Postgraduate Institute of Medical Sciences, \\ Lucknow, India
}

\section{Key Words}

Choledochal cyst · Cholangitis · Hepatolithiasis ·

Pancreatitis · Biliary spontaneous perforation · Portal

hypertension · Biliary tract malignancy

\begin{abstract}
Objectives: The presentation of choledochal cysts (CDCs) is altered by complications such as acute severe cholangitis, hepatolithiasis, spontaneous perforation, portal hypertension, pancreatitis, malignancy of the biliary tract and previous surgery in the form of internal drainage of the cyst. The management and the outcome of such complicated cysts differ from that of an uncomplicated CDC. This presentation is an analysis of our experience with complicated CDCs. Patients and Methods: One hundred and forty-four patients with CDCs were managed at a tertiary level referral hospital in North India, between January 1989 and June 2004. Thirty-three (23\%) CDCs were associated with complicating factors: severe cholangitis requiring a biliary drainage procedure prior to definitive operative procedure ( $n=11)$, spontaneous perforation ( $n=3$ ), hepatolithiasis ( $n=6)$, acute cholecystitis ( $n=1)$, recurrent acute pancreatitis $(n=1)$, chronic pancreatitis ( $n=1)$, gastric outlet obstruction ( $n=1)$, portal hypertension ( $n=6)$, biliary tract malignancy $(n=4)$ and previous internal drainage of the cyst $(n=5)$. Five patients had more than one complication.
\end{abstract}

The management outcome of complicated CDCs was compared with that of uncomplicated CDCs. Results: Complicated CDCs were significantly more common with type IV-A anatomy. Endoscopic, percutaneous or external surgical biliary drainage procedure was performed in 14 complicated CDCs prior to cyst excision. Desired definitive surgical procedure could be performed in 26/33 (79\%) patients with complicated CDCs as compared to $107 / 111$ (96\%) patients with uncomplicated CDCs. Four (12\%) patients with complicated CDCs had early postoperative complications as compared to 9/111 $(8 \%)$ patients with uncomplicated CDCs. During a median follow-up of 13 months (2 months to 8 years), 2 patients with complicated CDCs died due to advanced secondary biliary cirrhosis and advanced gall bladder cancer, respectively. Six patients reported complications. Of the 6 patients, 3 required reoperation for a strictured hepaticojejunostomy $(n=2)$ and hepatolithiasis $(n=1)$. In contrast, there was no disease-related mortality and only 1 out of 111 patients with uncomplicated cysts had a complication during follow-up. Conclusion: Complicated CDCs merit a carefully planned management strategy including percutaneous, endoscopic and surgical procedures. The management may have to be staged. The outcome depends on the nature of complication and the management strategy adopted.

Copyright (C) 2007 S. Karger AG, Basel

Prof. Rajan Saxena, Department of Surgical Gastroenterology, Sanjay Gandhi Postgraduate Institute of Medical Sciences, Raebareli Road

Lucknow 226014 (India)

Tel. +91 5222668004008 (EPABX), ext. 2425/2403, Fax +91 5222668017

E-Mail rajan@sgpgi.ac.in 
Fig. 1. Classification of CDCs.

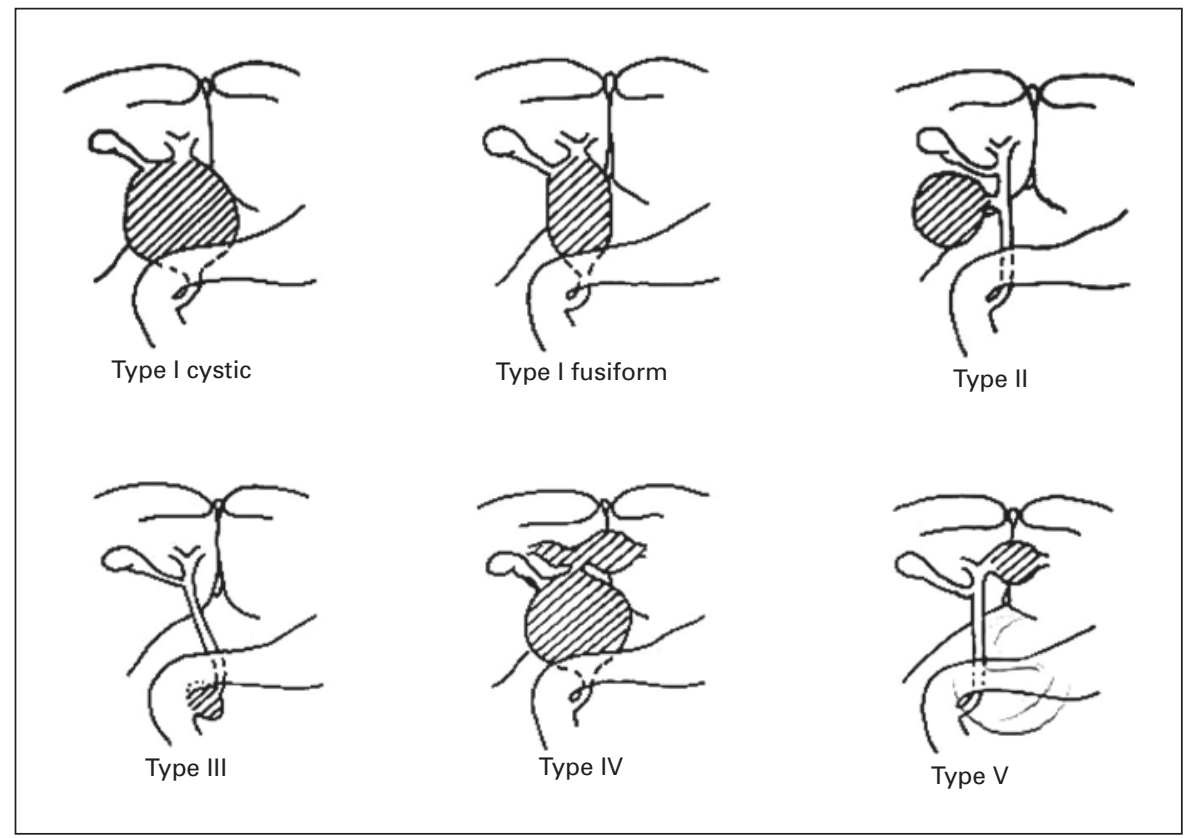

\section{Introduction}

Choledochal cysts (CDCs) commonly present with pain abdomen, jaundice and abdominal lump in various combinations $[1,2]$. However, the presence of various cyst-related complications may alter the classical presentation and also influence the subsequent management and outcome. Few reports have specifically addressed the problems associated with the management and outcome of complicated CDCs [3, 4]. This study highlights our experience with complicated CDCs. We have also recently reported our experience with 35 cases of type IV-A CDCs treated between January 1989 and December 2002 [5].

\section{Patients and Methods}

Data on 144 patients with CDCs, managed between January 1989 and June 2004, at a tertiary level referral hospital in North India, were analyzed retrospectively. There were 76 adults and 68 children in this group. The cyst types were: type I $(n=86)$, type III $(n=1)$, type IV $(n=56)$ and the 'forme fruste' variant $(n=1)$. Figure 1 gives the diagrammatic representation of various cyst types. There were 21 adults (64\%) and 12 children (36\%, 4 infants) ranging in age from 4 months to 60 years with a female preponderance $(19 / 13 ; \mathrm{m}: \mathrm{f}=0.7: 1)$. Thirty-three of these $144(23 \%)$ cases presented with complications and these were: acute suppurative cholangitis warranting a preoperative biliary drainage $(n=1)$, acute cholecystitis $(n=1)$, spontaneous cyst perforation $(n=3)$, hepatolithiasis $(n=6)$, recurrent acute pancreatitis $(n=1)$, chronic pancreatitis $(\mathrm{n}=1)$, gastric outlet obstruction $(\mathrm{n}=1)$, portal hypertension $(n=6)$, biliary tract malignancy $(n=4)$ and previous surgery in the form of internal drainage of the cyst $(n=5)$. The duration of symptoms ranged from 3 months to 30 years (median 2 years). The imaging studies used were: abdominal ultrasonography $(n=33)$, contrast-enhanced computed tomographic scan of the abdomen $(n=9)$, endoscopic retrograde cholangiopancreatogram $(n=8)$, magnetic resonance cholangiopancreatogram (MRCP; $n=4)$, and intraoperative cholangiogram $(n=2)$.

Statistical analysis was done using the Fisher's exact test. Statistical significance was defined as $\mathrm{p}<0.05$.

\section{Results}

The cyst types in 33 patients with complicated CDC were: type I $(n=11)$, type III $(n=1)$ and type IV $(n=21)$. Complications found to be associated with the different anatomical cyst types are listed in table 1.

Acute suppurative cholangitis $(n=11)$, unresponsive to intravenous antibiotics, required preoperative biliary drainage in all patients in the form of a percutaneous transhepatic biliary drainage $(n=10)$ and a surgical drainage with a T-tube choledochocystostomy $(n=1)$. One patient died of cholangitis and septicemia leading to multisystem organ failure despite a percutaneous biliary drainage. Cyst excision was performed successfully 6-12 weeks later in 8 of the 10 remaining patients. Two patients did not report for definitive surgery after a biliary drainage procedure. 
Table 1. Complicated CDCs and cyst anatomy

\begin{tabular}{|c|c|c|}
\hline Nature of complication & Patients & Cyst type \\
\hline Acute suppurative cholangitis & 11 & $\begin{array}{lr}\text { I } \quad(n=3) \\
\text { IV-A }(n=8)\end{array}$ \\
\hline Acute cholecystitis & 1 & IV $-\mathrm{A}(\mathrm{n}=1)$ \\
\hline Spontaneous perforation & $3^{\mathrm{a}}$ & $\begin{array}{lr}I \quad(n=1) \\
\text { IV-A }(n=2)\end{array}$ \\
\hline Hepatolithiasis & $6^{\mathrm{a}}$ & IV $-A(n=6)$ \\
\hline Recurrent acute pancreatitis & 1 & III $\quad(\mathrm{n}=1)$ \\
\hline Chronic calcific pancreatitis & 1 & IV-A $(\mathrm{n}=1)$ \\
\hline Gastric outlet obstruction & 1 & IV-A $(n=1)$ \\
\hline Portal hypertension & $6^{\mathrm{a}}$ & $\begin{array}{lr}\text { I } & (n=2) \\
\text { IV-A } & (n=4)\end{array}$ \\
\hline Biliary tract malignancy & 4 & $(\mathrm{n}=4)$ \\
\hline Previous internal drainage & $5^{\mathrm{a}}$ & $\begin{array}{lr}I \quad(n=1) \\
\text { IV-A }(n=4)\end{array}$ \\
\hline
\end{tabular}

${ }^{\text {a }}$ More than 1 complication was present in 5 patients.

Spontaneous cyst perforation presented as bile peritonitis $(n=2)$ and localized subhepatic biloma $(n=1)$. The initial management was a percutaneous drainage for the biloma $(\mathrm{n}=1)$ and a T-tube choledochocystostomy and peritoneal lavage for bile peritonitis $(n=2)$. Cyst excision $(\mathrm{n}=3)$ was performed 6-12 weeks later.

All 6 patients with hepatolithiasis had type IV-A anatomy with a history of recurrent cholangitis. One patient required preoperative biliary drainage for the same. Cyst excision was performed in all 6 patients. One of these 6 patients subsequently required a left lateral segmentectomy because of recurrent cholangitis consequent to intrahepatic cystic dilatations and calculi largely limited to the left lateral segment.

Recurrent episodes of acute pancreatitis presented in 1 patient with choledochocele. Endoscopic deroofing had to be abandoned in this patient because of bleeding, and the patient was then successfully managed surgically with transduodenal sphincteroplasty.

One patient had associated symptomatic chronic pancreatitis with a drainable pancreatic duct on MRCP. Hence, a lateral pancreaticojejunostomy along with cyst excision and roux-en-y hepaticojejunostomy was performed.

Another patient presented with gastric outlet obstruction due to extrinsic compression by the cyst which resolved following cyst excision.

Portal hypertension $(n=6)$ manifested as hematemesis $(n=2)$, refractory ascites $(n=3)$, and with ascites, jaundice and cholangitis $(n=1)$. The cause of portal hyperten- sion was secondary biliary cirrhosis $(\mathrm{n}=5)$ and extra hepatic portal vein thrombosis (EHPVO) probably secondary to recurrent cholangitis $(n=1)$. Shunt surgery for portal decompression was attempted in the patient with EHPVO but was unsuccessful. Cyst excision was performed successfully in 3 out of 6 patients. In 2 patients, an internal drainage of cyst was resorted to because of excessive bleeding from the collaterals in the hepatoduodenal ligament. One patient did not report for definitive surgery after a percutaneous biliary drainage for recurrent severe cholangitis.

Four patients, all presenting with jaundice, were detected to have an associated biliary tract malignancy at presentation. These were: locally advanced gall bladder cancer (infiltrating into the liver and hepatoduodenal ligament; $n=2)$; lower end cholangiocarcinoma $(n=1)$, and an ampullary carcinoid tumor $(\mathrm{n}=1)$. Cholecystectomy and internal drainage $(n=2)$ were performed for gall bladder carcinoma; cyst excision was not done due to the advanced stage of malignancy. The other 2 patients successfully underwent a pylorus-preserving pancreatico-duodenal resection (PPPDR).

Five patients presented after a previous internal drainage of the CDC (choledochocystoduodenostomy in 4, and choledochocystogastrostomy in 1 patient) performed elsewhere. All 5 patients, presented with recurrent pain, jaundice and cholangitis. Two patients required a preoperative biliary drainage for control of cholangitis refractory to antibiotics. Cyst excision was performed successfully in all 5 patients.

The overall management approach is summarized in table 2 . The desired surgical procedure could be performed in 26 patients (79\%). These were: cyst excision $(\mathrm{n}=23)$, PPPDR $(\mathrm{n}=2)$ and transduodenal sphincteroplasty $(n=1)$ for choledochocele.

One patient died of acute myocardial infarction in the postoperative period. Nonfatal complications were observed in $4(12 \%)$ patients. These were: hepaticojejunostomy leak $(n=3)$ and a low output controlled external pancreatic fistula $(n=1)$. The bile leak responded to percutaneous biliary diversion in all 3 cases, while the controlled external pancreatic fistula closed spontaneously.

Follow-up information was available for 24 (77\%) patients (range 2 months to 8 years, mean $22 \pm 25$ months, and median 13 months) in the complicated cyst group. While on follow-up, 2 patients died of advanced gall bladder cancer and liver failure, respectively. Of the remaining 22 patients, 4 patients who had had total cyst excision developed recurrent cholangitis on account of anastomot- 
Table 2. Management of complicated CDCs

\begin{tabular}{|c|c|c|}
\hline Complication & $\begin{array}{l}\text { First stage surgical/ } \\
\text { nonsurgical intervention }\end{array}$ & $\begin{array}{l}\text { Definitive surgical } \\
\text { procedures }\end{array}$ \\
\hline $\begin{array}{l}\text { Acute severe } \\
\text { cholangitis } \\
(\mathrm{n}=11)\end{array}$ & $\begin{array}{l}\text { Endoscopic/percutaneous } \\
\text { transhepatic biliary } \\
\text { drainage }(n=10) \\
\text { Surgical external } \\
\text { drainage }(n=1)\end{array}$ & Cyst excision $(\mathrm{n}=8)^{\mathrm{a}}$ \\
\hline $\begin{array}{l}\text { Hepatolithiasis } \\
(\mathrm{n}=6)\end{array}$ & $\begin{array}{l}\text { Percutaneous } \\
\text { transhepatic biliary } \\
\text { drainage }(\mathrm{n}=1)^{\mathrm{b}}\end{array}$ & Cyst excision $(n=6)$ \\
\hline $\begin{array}{l}\text { Spontaneous } \\
\text { cyst perforation }(n=3)\end{array}$ & $\begin{array}{l}\text { External biliary drainage } \\
\text { of the cyst }(n=2) \\
\text { Percutaneous drainage } \\
\text { of biloma }(n=1)\end{array}$ & Cyst excision $(n=3)$ \\
\hline $\begin{array}{l}\text { Acute } \\
\text { pancreatitis }(n=1)\end{array}$ & $\begin{array}{l}\text { Endoscopic papillotomy } \\
\text { (failed) }\end{array}$ & $\begin{array}{l}\text { Transduodenal } \\
\text { sphincteroplasty }(n=1)\end{array}$ \\
\hline $\begin{array}{l}\text { Chronic calcific } \\
\text { pancreatitis }(n=1)\end{array}$ & nil & $\begin{array}{l}\text { Cyst excision + lateral } \\
\text { pancreaticojejunostomy }(n=1)\end{array}$ \\
\hline $\begin{array}{l}\text { Gastric outlet } \\
\text { obstruction }\end{array}$ & nil & Cyst excision $(\mathrm{n}=1)$ \\
\hline $\begin{array}{l}\text { Portal hypertension } \\
(\mathrm{n}=6)\end{array}$ & $\begin{array}{l}\text { Splenectomy }+ \\
\text { devascularization }(n=1) \\
\text { Percutaneous } \\
\text { cholecystostomy }(n=1) \\
\text { Percutaneous transhepatic } \\
\text { biliary drainage }(n=1)^{b}\end{array}$ & $\begin{array}{l}\text { Cyst excision }(n=3) \\
\text { Internal drainage of } \\
\text { cyst }(n=2) \\
(1 \text { patient lost to follow-up) }\end{array}$ \\
\hline $\begin{array}{l}\text { Biliary tract malignancy } \\
(\mathrm{n}=4)\end{array}$ & nil & $\begin{array}{l}\text { Cholecystectomy }+ \text { internal } \\
\text { cyst drainage }(n=2) \\
\text { Pancreaticoduodenal } \\
\text { resection }(n=2)\end{array}$ \\
\hline $\begin{array}{l}\text { Previous internal } \\
\text { drainage }(n=5)\end{array}$ & $\begin{array}{l}\text { Percutaneous } \\
\text { transhepatic biliary } \\
\text { drainage/endoscopic } \\
\text { drainage }(\mathrm{n}=2)^{\mathrm{b}}\end{array}$ & Cyst excision $(n=5)$ \\
\hline
\end{tabular}

${ }^{\text {a }}$ One mortality despite percutaneous drainage; 2 cases lost to follow up after a percutaneous drainage.

${ }^{\mathrm{b}}$ Also included in the acute severe cholangitis group. ic stricture $(n=2)$ and hepatolithiasis $(n=2)$. Three of them underwent reoperation: revision of hepaticojejunostomy $(\mathrm{n}=2)$ and left lateral segmentectomy $(\mathrm{n}=1)$. The fourth patient with cholangitis responded to antibiotics. The patient with EHPVO also developed recurrence of cholangitis after internal drainage of the cyst. This was managed by endoscopic biliary stenting. One patient, who underwent a PPPDR along with cyst excision for an associated ampullary carcinoid tumor developed stenosis of the pancreatojejunostomy anastomosis
3 years after the resection. A pancreaticogastrostomy was performed at revision surgery.

In patients with uncomplicated cysts $(\mathrm{n}=111)$, there were 2 early postoperative deaths. The causes were intraoperative portal vein injury $(n=1)$ with subsequent coagulopathy because of massive blood transfusion and biliary anastomotic leak leading to sepsis $(n=1)$. Nonfatal complications occurred in $9(8 \%)$ patients. These were: bilioenteric anastomotic leak $(\mathrm{n}=5$, biliary diversion in $1)$, external pancreatic fistula $(n=2$, closed spontane- 
Table 3. Comparison of complicated with uncomplicated CDCs

\begin{tabular}{lccc}
\hline Parameter & $\begin{array}{l}\text { Complicated cyst } \\
(\mathrm{n}=33)\end{array}$ & $\begin{array}{l}\text { Uncomplicated cyst } \\
(\mathrm{n}=111)\end{array}$ & $\mathrm{p}$ value \\
\hline Type IV-A anatomy & $21(64)$ & $35(31)$ & $0.001^{*}$ \\
Cyst excision & $26(79)$ & $107(96)$ & $0.003^{*}$ \\
$\begin{array}{l}\text { Internal drainage procedures } \\
\text { Early postoperative complications }\end{array}$ & $5(22)$ & $4(4)$ & $0.02^{*}$ \\
$\begin{array}{l}\text { Delayed complications } \\
\quad \text { (including mortality) }\end{array}$ & $8(33)$ & $11(10)$ & 0.35 \\
\hline
\end{tabular}

Figures in parentheses indicate percentages. * p value significant. ously) and intra-abdominal bleed $(\mathrm{n}=2,1$ required reexploration).

Follow-up was available for $76(70 \%)$ patients with uncomplicated CDCs (range 1 month to 11 years, mean $17 \pm 24$ months, median 12 months). There were no disease-related deaths during follow-up. One patient developed anastomotic stricture extending into the right ductal system for which a right hepatectomy was performed.

The patients with complicated CDCs were compared with those with uncomplicated cysts (table 3). Complicated CDCs were frequently of type IV-A anatomy; at surgery, complete excision was less likely, and these patients had internal drainage procedures more often. At follow-up, disease-related mortality and long-term complications were more common in the complicated CDCs group.

\section{Discussion}

Complicated CDCs were more frequently of type IV-A anatomy in this series, and this has also been observed in the literature $[3,6,7]$. Type IV-A cysts by virtue of their intrahepatic cystic component and intrahepatic bile stasis, are more prone to develop complications [8].

Complications related to CDCs have been broadly divided into infective and noninfective complications [3]. Amongst the infective complications, fulminant cholangitis is common, especially in adults [9, 10]. Failure to respond to intravenous antibiotics should prompt an early percutaneous or endoscopic biliary drainage; external surgical drainage of the cyst may occasionally be required when a percutaneous or an endoscopic procedure fails to provide adequate biliary decompression, as was experienced in one of our patients. Excision of the CDC in presence of acute suppurative cholangitis has been reported to be associated with high morbidity and mortality. Staged management in the form of an initial biliary decompression followed by cyst excision 6-12 weeks after the control of cholangitis, has been found to give a satisfactory outcome [3, 11-14].

Spontaneous perforation of $\mathrm{CDC}$ is rare, reported in $1-2 \%$ of cases $[15,16]$. The etiopathogenesis of these perforations has been attributed to a sudden rise in intracystic pressure as a result of the blockage of the common channel by a protein plug, compounded by weakening of the cyst wall by recurrent chemical cholangitis secondary to long-standing reflux of pancreatic juice into the biliary system $[17,18]$. These patients present with bile peritonitis and the diagnosis is confirmed by bile aspiration on abdominal paracentesis together with an ultrasonographic documentation of a CDC. The recommended management is emergency laparotomy, peritoneal lavage and external biliary drainage preferably by a T-tube inserted into the CDC [17]. The perforation may sometimes present as a localized bile collection (biloma), which may be managed by percutaneous drainage. Complete cyst excision with a bilioenteric reconstruction performed 6-12 weeks after the drainage procedure gives a satisfactory outcome as was observed in our patients.

Hepatolithiasis is more often associated with intrahepatic cystic dilatations with or without downstream congenital ductal stenosis [7]. An intraoperative cyst endoscopy is a valuable aid in detecting and washing off the intrahepatic ducts of calculi and debris [7].

For residual intrahepatic calculi, a 'jejunal access limb' provides a useful access for subsequent choledochoscopic clearance of the intrahepatic biliary tree. Percutaneous transhepatic cholangioscopy and lithotripsy is another useful approach to the management of intrahepatic calculi [7]. Hepatic resection may be indicated for calculi and cysts limited to one part of the liver causing recurrent cholangitis and segmental fibrosis. One of our patients did require a left lateral segmentectomy for the same purpose. 
The association of acute or chronic pancreatitis with $\mathrm{CDC}$ has been explained by an underlying anomalous pancreaticobiliary junction which permits free intermixing of pancreatic and biliary juices and protein plugs in the common channel. The incidence of acute pancreatitis with CDCs has been variously quoted to range from 0 to $70 \%$ [19-21]. The true incidence of pancreatitis with $\mathrm{CDC}$ is difficult to decipher from the literature because serum amylase or lipase levels are not routinely done for pain abdomen in patients with $\mathrm{CDC}$, and the definition of pancreatitis in the setting of $\mathrm{CDC}$ is variable. Todani et al. [22] described patients with CDC who had recurrent bouts of abdominal pain and mild elevation in serum amylase but no evidence of pancreatitis at surgery. This 'psuedopancreatitis' and hyperamylasemia was associated with high biliary amylase levels and attributed to pancreaticobiliary reflux. While most episodes of pancreatitis are mild and can be managed conservatively, recurrences can only be eliminated by cyst excision and biliopancreatic disconnection [19-23].

In patients with associated symptomatic chronic pancreatitis, treatment options include: cyst excision combined with a lateral pancreaticojejunostomy if the pancreatic duct is adequately dilated or pancreaticoduodenectomy for predominantly pancreatic head pathology [24-28].

Choledochoceles, per se, are rare but are more often known to present as pancreatitis; the incidence in the literature varies from 19 to $45 \%$. The treatment of choice in the current era is endoscopic deroofing of the choledochocele together with an adequate sphincterotomy to permit free drainage of the pancreaticobiliary tree. Surgery is indicated for large choledochoceles, suspicion of a mass lesion within the cyst or failure of endoscopic therapy as was the indication in our patient [29].

Portal hypertension in CDCs may be secondary to biliary cirrhosis, compression of the portal vein by the CDC or portal vein thrombosis [30-32]. Excision of the CDC in the presence of portal hypertension is a major and hazardous undertaking due to the presence of extensive collaterals in the hepatoduodenal ligament and may be associated with increased postoperative morbidity and mortality [33]. Cyst excision may have to be abandoned in favor of internal drainage in these patients [3, 6, 34]. Decompression of the portal venous system in the form of a portosystemic shunt may be required before the cyst can be approached for excision, especially in patients who have bled from the varices [35]. In the current series, cyst excision could be achieved in only 3 of 6 patients, while internal drainage had to be performed in 2 patients. $\mathrm{Pa}$ -

tients with advanced biliary cirrhosis and portal hypertension would eventually merit liver transplantation.

A malignancy of the biliary tract is associated with CDC in $2.5-26 \%$ of cases, and carries a dismal prognosis on account of delayed diagnosis, advanced stage at presentation and multicentricity of the lesion [36-41]. This translates into fewer radical resections, and even after radical resection, most patients succumb within 2 years of the diagnosis [42, 43].

It is estimated that $13-69 \%$ of patients who have had an internal drainage procedure would need reoperation for abdominal pain, jaundice, recurrent cholangitis, calculi, pancreatitis and portal hypertension because of strictured cystenterostomy and stasis within the retained cyst $[6,34,44,45]$. It is also estimated that the risk of malignancy in the retained cysts may be as high as 50\% [15]. Reoperation and excision of the cyst in these patients may not be an easy task on account of extensive fibrosis and/or portal hypertension. Excision of the cyst was, however, performed successfully in all 5 patients with previous internal drainage in our series. It has been recommended that cyst excision should be performed in all patients who have had a prior internal drainage, even if asymptomatic [46-48].

Management strategy for complicated CDCs needs meticulous planning and multimodality approach. The therapeutic strategy needs to be tailored to an individual case. Percutaneous and endoscopic biliary drainage procedures are useful adjuncts to the surgical management, which itself may have to be a multistaged process. The outcome is satisfactory in patients with appropriately managed infective complications. The presence of portal hypertension or malignancy may preclude a technically satisfactory cyst excision in many instances, and the ultimate prognosis is largely governed by the progression of liver pathology or malignancy.

References

Dig Surg 2007;24:456-462
1 Howard ER: Choledochal cysts; in Schwartz SI, Ellis H (eds): Maingot's Abdominal Operations, ed 9. Norwalk, Appleton and Lange, 1989, pp 1365-1380.

-2 Sela-Herman S, Scharschmidt BF: Choledochal cysts, a disease for all ages. Lancet 1996;347: 779-782.

-3 Chaudhary A, Dhar P, Sachdev AK: Complicated choledochal cysts. Int Surg 2001;86:97102.

4 Hopkins NF, Benjamin IS, Thompson MH: Complications of choledochal cysts in adults. Ann R Coll Surg Engl 1990;72:229-235. 
$\checkmark 5$ Lal R, Agarwal S, Shivhare R, Kumar A, Sikora SS, Saxena R, et al: Type IV-A choledochal cysts - a challenge. J Hepatobiliary Pancreat Surg 2005;12:129-134.

$\checkmark 6$ Chaudhary A, Dhar P, Sachdev AK: Choledochal cysts-differences in adults and children. Br J Surg 1996;83:186-188.

7 Yamataka A, Oshiro K, Okada Y: Complications after cyst excision with hepaticoenterostomy for choledochal cysts and their surgical management in children versus adults. J Pediatr Surg 1997;32:1097-1102.

-8 Uno K, Tsuchida Y, Kawarasaki H: Development of intrahepatic cholelithiasis after primary excision of choledochal cysts. J Am Coll Surg 1996;183:583-588.

$\checkmark 9$ Hewitt PM, Krige JEJ, Bornman PC, et al: Choledochal cysts in adults. Br J Surg 1995;82: 382-385.

10 Visser BC, Suh I, Way WL: Congenital choledochal cysts in adults. Arch Surg 2004;139: 855-860.

$\checkmark 11$ Moir CR, Scudmore CH: Emergency management of choledochal cysts in adult patients. Am J Surg 1987;153:434-438.

12 Nagorney DM: Bile duct cysts in adults; in Blumgart LH, Fong Y (eds): Surgery of the Liver and Biliary Tract, ed 3. Philadelphia, Saunders, pp 1229-1244.

13 Yukihiro I, Kimura K: Choledochal cysts and related anomalies; in Donnellan WL, Burrington JD, Kimura K, Schafer JC, White JJ (eds): Abdominal Surgery of Infancy and Childhood. London, Harwood Academic Publishers, 1996, chapter 33.

14 Howard ER: Choledochal cysts; in Howard ER (ed): Surgery of Liver Diseases in Children. Boston, Butterworth Heinemann, pp 78-90.

$\checkmark 15$ Yamaguchi M: Congenital choledochal cysts; analysis of 1433 patients in the Japanese literature. Am J Surg 1980;140:653-657.

$\checkmark 16$ Yamashiro Y, Sato M, Hoshino A: Spontaneous perforation of choledochal cyst. Eur J Pediatr 1982;138:193-195.

-17 Ando H, Ito T, Watanabe Y, Seo T: Spontaneous perforation of choledochal cyst in childhood. J Am Coll Surg 1995; 181:125-128.

18 Ohkawa H, Takahashi H, Maie M: A malformation of the pancreatobiliary system as a cause of perforation of the biliary tract in childhood. J Pediatr Surg 1977; 12:541-546.
19 Altman S, Halls JM, Douglas AP: Choledochal cyst presenting as acute pancreatitis. Am J Gastroenterol 1978;70:514-519.

20 Buntain WL, Wood JL, Wooley MM: Pancreatitis in childhood. J Pediatr Surg 1978;13: 143-149.

21 Swisher SG, Cates JA, Bennion RS, et al: Pancreatitis associated with adult choledochal cysts. Pancreas 1994;9:633-637.

22 Todani T, Urushira N, Watanabe Y, et al Psuedopancreatitis in choledochal cyst in children: intraoperative study of amylase levels in the serum. J Pediatr Surg 1990;10:303-306.

23 Okada A, Oguchi Y, Kamata S, et al: Common
channel syndrome-diagnosis with endoscopic retrograde cholangiopancreatography and surgical management. Surgery 1983;93:634-641.

24 Crombleholme TM, delorimier AA, Way LW, et al: The modified Puestow procedure for chronic relapsing pancreatitis. J Pediatr Surg 1990;25:749-754.

-25 Jalleh RP, Williamson RC: Choledochal cyst and chronic pancreatitis treated with proximal pancreatectomy. HPB Surg 1991;4:245-249.

-26 Nakagohri T, Konishi M, Inoue K, et al: Inferior head resection of the pancreas and cyst resection for choledochal cyst with chronic calcifying pancreatitis. Hepatogastroenterology 2004;51:1504-1505.

27 Sugiyama M, Atomi Y, Kuroda A: Pancreatic disorders associated with anomalous pancreaticobiliary junction. Surgery 2000;127:596597.

28 Zhao L, Li Z, Ma H, et al: Congenital choledochal cysts with pancreatitis. Chin Med J (Engl) 1999;112:637-640.

29 Martin RF, Barbara PB, Bosco JJ: Symptomatic choledochoceles in adults. Arch Surg 1992; 127:536-539.

30 Martin W, Rowe GA: Portal hypertension secondary to choledochal cysts. Ann Surg 1979; 190:638-639.

31 Rao KL, Chowdhary SK, Kumar D: Choledochal cysts associated with portal hypertension. Pediatr Surg Int 2003;9:729-732.

32 Samuel M, Spitz L: Choledochal cysts: varied clinical presentation and long term results of surgery. Eur J Pediatr Surg 1996;6:78-81.
33 Nambirajan L, Taneja P, Singh MK: The liver in choledochal cysts. Trop Gastroenterol 2000; 21:135-139.

34 Tan KC, Howard ER: Choledochal cyst: a 14 year surgical experience with 36 patients. Br J Surg 1988;75:892-895.

35 Nagorney DM, Mcllrath DC, Adson MA: Choledochal cysts in adults: clinical management. Surgery 1984;96:656-663.

36 Fieber SS, Nance FC: Choledochal cysts and neoplasm; a comprehensive review of 106 cases and presentation of two original cases. Am Surg 1997;63:982-987.

37 Flanigan DP: Biliary cysts. Ann Surg 1975; 182:635-643.

38 Jan YY, Chen HM, Chen MF: Malignancy in choledochal cysts. Hepatogastroenterology 2000;47:337-340.

39 Rossi RL, Silverman ML: Carcinomas arising in cystic conditions of the bile ducts Ann Surg 1987;205:377-386.

40 Todani T, Watanabe Y, et al: Congenital choledochal cysts with intrahepatic involvement. Arch Surg 1984;119:1038-1043.

41 Todani T, Watanabe Y, Toki A: Carcinoma related to choledochal cysts with internal drainage operations. Surg Gynecol Obstet 1987; 164:61-64.

42 Liu CL, Fan ST, Lo CM: Choledochal cysts in adults. Arch Surg 2002;137:465-468.

43 Stain SC, Guthrie CR, Yellin AE: Choledochal cysts in adults. Ann Surg 1995;222:128-133.

44 Chijiiwa K, Koga A: Surgical management and long term follow up of patients with choledochal cysts. Am J Surg 1993;165:238-242.

$>45$ Komuro H, Makino SI, Yasuda Y, et al: Pancreatic complications in choledochal cysts and their surgical outcomes. World J Surg 2001;25: 1519-1523.

46 Chijiiwa K: Hazard and outcome of retreated choledochal cysts patients. Int Surg 1993;78: 204-207.

47 Karanikas ID, Koundourakis SS, Macheras AN, et al: Long term results of management of type I choledochal cysts in adults. Acta Chir Belg 1997;97:13-18.

48 Robertson JFR, Raine PAM: Choledochal cysts: a 33 year review. Br J Surg 1988;75:799801 . 